Check for updates

Cite this: Chem. Commun., 2019, 55, 12964

Received 17th September 2019, Accepted 2nd October 2019

DOI: $10.1039 / \mathrm{c} 9 \mathrm{cc} 07289 f$

rsc.li/chemcomm

\section{Calcium stannyl formation by organostannane dehydrogenation $\uparrow$}

\author{
Louis J. Morris, ${ }^{a}$ Michael S. Hill, (D)*a Ian Manners, ${ }^{b}$ Claire L. McMullin, (D) *a \\ Mary F. Mahon and Nasir A. Rajabi ${ }^{a}$
}

\begin{abstract}
Reaction of the dimeric calcium hydride, $[(\mathrm{BDI}) \mathrm{CaH}]_{2}$ (1), with $\mathrm{Ph}_{3} \mathrm{SnH}$ ensues with elimination of $\mathrm{H}_{2}$ to provide [(BDI)Ca- $\mu_{2}-\mathrm{H}-\left(\mathrm{SnPh}_{3}\right) \mathrm{Ca}(\mathrm{BDI})$ ] (3) and $\left[(\mathrm{BDI}) \mathrm{Ca}\left(\mathrm{SnPh}_{3}\right)\right]_{2}$ (4) alongside dismutation to $\mathrm{Ph}_{4} \mathrm{Sn}, \mathrm{H}_{2}$ and $\mathrm{Sn}(0)$. DFT analysis indicates that stannyl anion formation occurs through deprotonation of $\mathrm{Ph}_{3} \mathrm{SnH}$ and with retention of dinuclear species throughout the reactions.
\end{abstract}

The stoichiometric and catalytic reaction chemistry of heavier alkaline earth species, particularly those of calcium, continues to attract increasing attention. ${ }^{1}$ Central to these advances have been a suite of highly nucleophilic molecular hydride derivatives, ${ }^{2,3}$ which may be applied to an array of reductive multiple bond heterofunctionalisation and cross-metathetical processes. ${ }^{4}$ Our own recent research has concentrated on the coordinatively unsaturated $\beta$-diketiminato derivative $[(\mathrm{BDI}) \mathrm{CaH}]_{2}(\mathbf{1} ; \mathrm{BDI}=\mathrm{HC}\{(\mathrm{Me}) \mathrm{CN}-2,6-\mathrm{i}-$ $\left.\operatorname{Pr}_{2} \mathrm{C}_{6} \mathrm{H}_{3}\right\}_{2}$ : Scheme 1), which reacts directly with a wide range of otherwise unactivated alkenyl $\mathrm{C}=\mathrm{C}$ bonds. ${ }^{5,6}$ The resultant calcium $\sigma$-organometallics have proven to be incredibly potent reagents in their own right and are capable of effecting the direct alkylation of benzene via an unprecedented displacement of hydride (to reform 1), and in which the polarising qualities of the calcium centre itself perform a key role (Scheme 1).

As an extension of this work, we have turned our attention to the potential of calcium derivatives of the heavier tetrels to effect similarly challenging arene activation. The realisation of such processes would enable the direct nucleophilic access to triorganosilylated and triorganostannylated aryl derivatives which would themselves be valuable substrates for onward elaboration in, for example, catalytic Hiyama- ${ }^{8}$ or Stille-type cross coupling protocols. ${ }^{9}$ Although organostannyl anions of

\footnotetext{
${ }^{a}$ Department of Chemistry, University of Bath, Claverton Down, Bath, BA2 7AY, UK. E-mail:msh27@bath.ac.uk

${ }^{b}$ Department of Chemistry, University of Victoria, Victoria, BC V8P 5C2, Canada $\dagger$ Electronic supplementary information (ESI) available: General synthetic experimental details, NMR spectra, X-ray analysis of compounds 3 and $\mathbf{4}$, details of the computational analysis and atomic coordinates of the DFT computed structures. CCDC 1951246 and 1951247. For ESI and crystallographic data in CIF or other electronic format see DOI: 10.1039/c9cc07289f
}

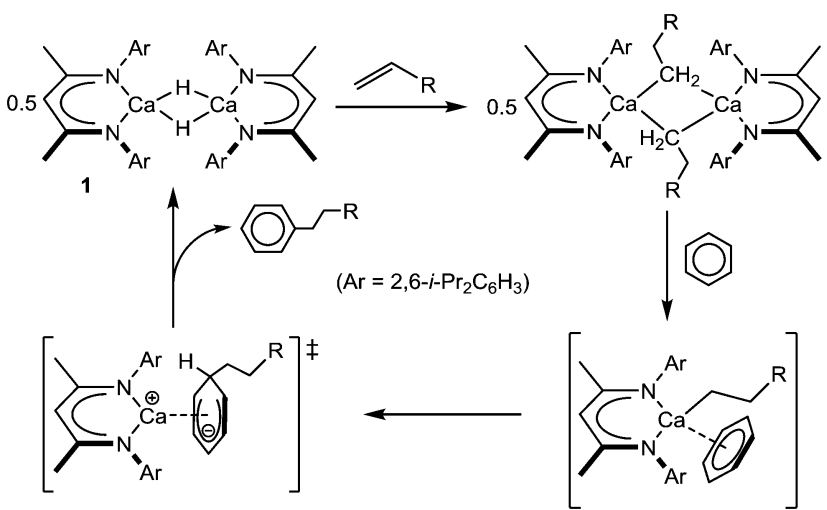

Scheme 1 Reaction of compound 1 with alkenes and the calciummediated nucleophilic alkylation of benzene.

the group 1 metals have received significant attention, ${ }^{10}$ calcium compounds containing bonds to heavier p-block elements are, in general, very rare, ${ }^{3,11}$ while the sole example of a direct calciumto-tin bond is provided by Westerhausen's bis(trimethylstannyl), $\left[\left(\mathrm{Me}_{3} \mathrm{Sn}\right)_{2} \mathrm{Ca}(\mathrm{THF})_{4}\right](2) .{ }^{12}$ Although the route to this compound, by treatment of calcium metal with hexamethyldistannane, provided a reasonable yield of the stannyl product its heterogeneous nature necessitated a long reaction time. For phenyl-tin derivatives, the intermolecular migration of phenyl substituents can also provide a significant complication. Of most relevance to the current work, Uhlig and co-workers have reported that reaction of metallic calcium with hexaphenyldistannane provided the charge separated species, $\left[\mathrm{Ca}(18 \text {-crown-6)(HMPA })_{2}\right]\left[\mathrm{Sn}\left(\mathrm{SnPh}_{3}\right)_{3}\right]_{2} \cdot{ }^{13}$ Herein, we report facile access to triphenylstannyl-calcium derivatives through the reaction of compound $\mathbf{1}$ and commercially available $\mathrm{Ph}_{3} \mathrm{SnH}$.

Addition of 2-3 equivalents of $\mathrm{Ph}_{3} \mathrm{SnH}$ to a $\mathrm{C}_{6} \mathrm{D}_{6}$ solution of compound $\mathbf{1}$ induced a rapid bubbling and the gradual development of a pale orange colouration. Analysis by ${ }^{119} \mathrm{Sn}\left\{{ }^{1} \mathrm{H}\right\}$ NMR spectroscopy after 60 minutes revealed quantitative consumption of the tin hydride and the appearance of a major new resonance at $\delta-139.8 \mathrm{ppm}$, which appeared alongside a lower 


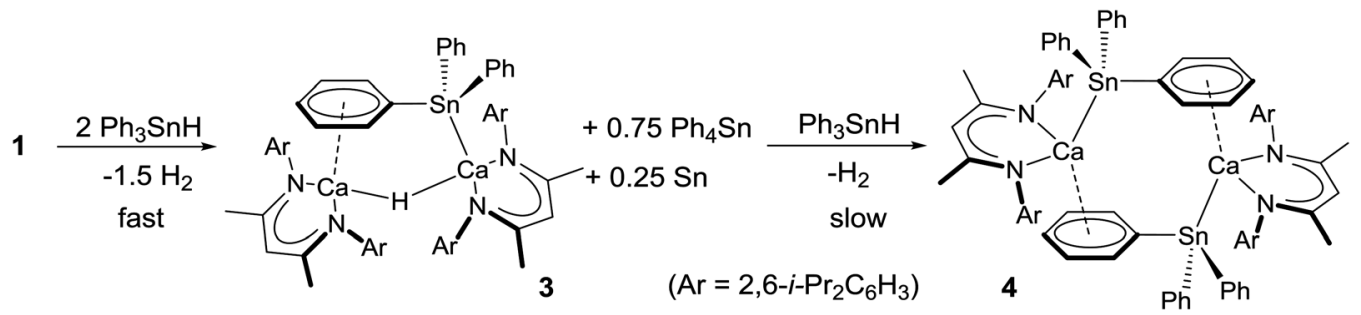

Scheme 2 Synthesis of compounds $\mathbf{3}$ and $\mathbf{4}$ and the calcium-centred dismutation of $\mathrm{Ph}_{3} \mathrm{SnH}$.

intensity signal at $\delta-126 \mathrm{ppm}$ and was readily identified as $\mathrm{Ph}_{4} \mathrm{Sn}$ by comparison to literature values. ${ }^{14}$ The corresponding ${ }^{1} \mathrm{H}$ NMR spectrum evidenced the formation of a predominant BDI-containing compound (3, Scheme 2) that was most readily characterised by the emergence of a new BDI $\gamma$-methine signal at $\delta 4.75 \mathrm{ppm}$ and a singlet, resonating with half the relative intensity, at $\delta 3.83 \mathrm{ppm}$. This latter signal also displayed characteristic satellites separated by $94 \mathrm{~Hz}$, within the typical range for a ${ }^{2} J\left({ }^{119 / 117} \mathrm{Sn}-{ }^{1} \mathrm{H}\right)$ coupling. ${ }^{14}$

While no significant changes to the NMR spectra were observed on standing overnight, the origin of these observations was resolved by an X-ray diffraction analysis, which was performed on a colourless single crystal grown from a hexane/toluene solution at $-30{ }^{\circ} \mathrm{C}$. The results of this analysis (Fig. 1) confirmed that compound 3 is an unsymmetrical dinuclear calcium species in which two $\{(\mathrm{BDI}) \mathrm{Ca}\}$ units are connected by $\mu_{2}$-bridging hydride and triphenylstannyl ligands.

The tin-centred ligand is bonded to $\mathrm{Ca} 2$ through $\mathrm{Sn} 1$ and interacts with Ca1 via an $\eta^{6}$-interaction of its (C70-C75) phenyl substituent. The significance of secondary interactions in the

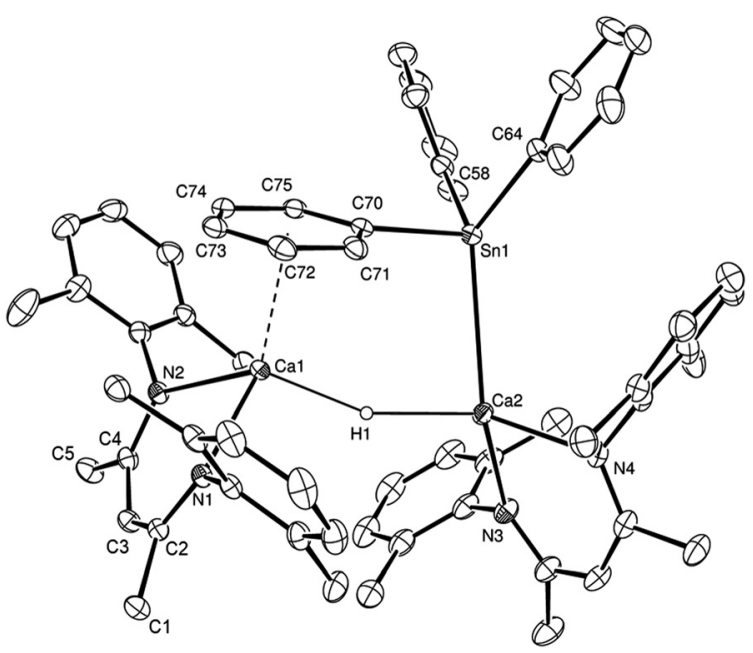

Fig. 1 ORTEP representation of compound $\mathbf{3}$ (25\% probability ellipsoids). Hydrogen atoms, except $\mathrm{H} 1$, iso-propyl methyl groups and occluded solvent molecules are removed for clarity. Selected bond lengths $(\AA)$ and angles

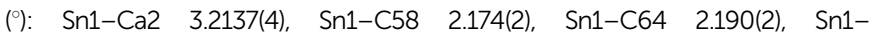
C70 2.2258(19), Ca1-N1 2.3443(16), Ca1-N2 2.3318(15), Ca1-C70 3.0649(18), Ca1-C71 2.9837(19), Ca1-C72 2.904(2), Ca1-C73 2.864(2), Ca1-C74 2.898(2), Ca1-C75 2.9815(19), Ca2-N3 2.3275(18), Ca2-N4 2.3306(17), C58-Sn1-Ca2 127.45(6), C58-Sn1-C64 98.00(8), C58-Sn1-C70 98.48(8), C64-Sn1-Ca2 129.08(6), C64-Sn1-C70 98.61(7), C70-Sn1-Ca2 96.16(5), N1-Ca1-N2 79.59(5), N3-Ca2-N4 81.18(6). stabilisation of alkaline-earth complexes is well established. ${ }^{15}$ Although unsupported $\eta^{6}$-arene interactions between benzene and toluene and calcium-centred cations have recently been observed by our own group ${ }^{16}$ and by Harder and co-workers, ${ }^{17}$ these structures display significantly longer $\mathrm{Ca}$-arene centroid distances (ca. $2.9 \AA)$ than that observed in 3 [2.5999(9) $\AA]$. This latter distance is, thus, more typical of those observed in a variety of $N$-mesityl- and $N$-di-isopropylphenyl calcium amidinate and triazenide derivatives in which the arene substituent is a tethered component of the coordinated anion. ${ }^{18}$ Although the Ca2-Sn1 bond length [3.2137(4) $\AA$ ] is similar to that observed in Westerhausen's calcium trimethylstannyl $[2,3.2721(3) \AA],{ }^{12}$ the strength of this $\mathrm{Ca}$-arene interaction ensures that the coordination environment of the tin centre is significantly perturbed toward a trigonal pyramidal geometry. The C70-Sn1-Ca2 bond angle subtended by the apical C70-C75- containing phenyl substituent is just $96.16(5)^{\circ}$, whereas the sum of the C58-Sn1-Ca2, C58-Sn1C64 and C64-Sn1-Ca2 angles amounts to $354.5^{\circ}$, with Sn1 lying only $0.331(1) \AA$ out of the basal plane of the pyramid defined by $\mathrm{Ca} 2$, C58 and C64.

Repetition of the reaction in $\mathrm{d}_{8}$-toluene provided similar observations at $298 \mathrm{~K}$. Cooling of this sample to $246 \mathrm{~K}$, however, resulted in significant broadening of the BDI $\gamma$-methine resonance at $\delta 4.71 \mathrm{ppm}$, which was observed to split into two well resolved signals at 4.60 and $4.83 \mathrm{ppm}$ below $211 \mathrm{~K}$. Although a single set of phenyl-tin resonances was also observed at $298 \mathrm{~K}$, below $220 \mathrm{~K}$ a series of resonances at $\delta 6.05,6.72$, and $8.10 \mathrm{ppm}$, and integrating in a $2: 1: 2$ ratio relative to the two $1 \mathrm{H}$ BDI $\gamma$-methine signals, could be discriminated. Although the Ca-Sn bond apparently rotates freely at room temperature, these latter signals may be attributed to the persistence of the Ca- $\eta^{6}$-phenyl interaction observed in the solid state structure $\left(\Delta G^{\ddagger}=48 \mathrm{~kJ} \mathrm{~mol}^{-1}\right)$.

When the reaction was left to stand for a further three days at room temperature the reaction mixture became opaque with the deposition of a brown-grey solid, which was tentatively assigned as a precipitate of Sn metal. Crystals of $\mathrm{Ph}_{4} \mathrm{Sn}$ (confirmed by a unit cell check), were also observed to form, coinciding with the emergence of a new signal at $\delta-160.6 \mathrm{ppm}$ in the ${ }^{119} \mathrm{Sn}\left\{{ }^{1} \mathrm{H}\right\}$ NMR spectrum. Removal of solvent from the reaction mixture, extraction of the solid residue into hexane/toluene and crystallisation at $-30{ }^{\circ} \mathrm{C}$ yielded single crystals of the hydride-free dimeric calcium triphenylstannyl, compound 4. Compound 4 (Fig. 2) is a centrosymmetric dimer, in which each pseudo-four-coordinate calcium centre is bound by a BDI ligand and a direct $\mathrm{Ca}-\mathrm{Sn}$ $\sigma$ bond to a triphenylstannyl anion. This $\mathrm{Ca}-\mathrm{Sn}$ distance is closely comparable to that of compound 3 [3.3221(6) $\AA]$. 


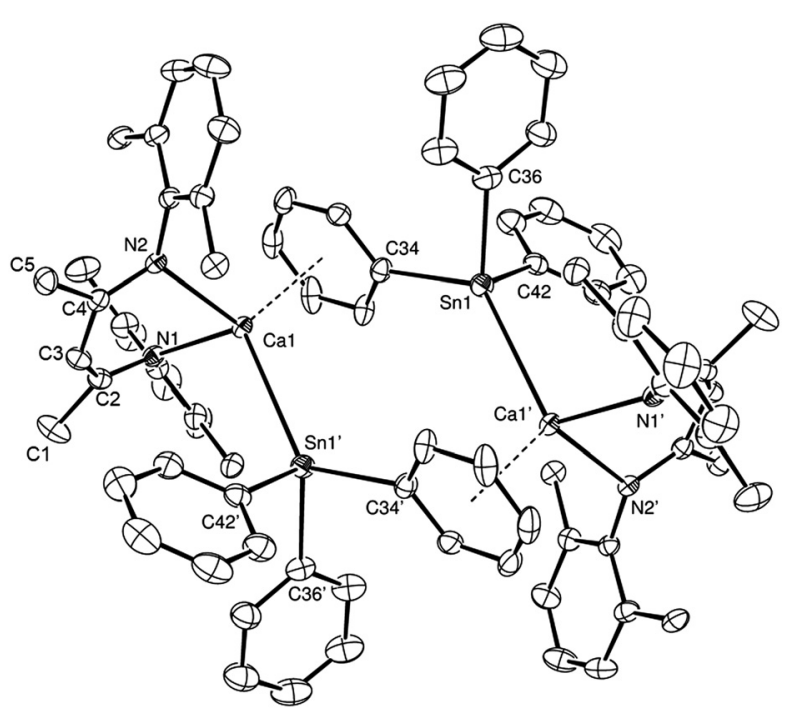

Fig. 2 ORTEP representation of compound $\mathbf{4}$ (25\% probability ellipsoids). Hydrogen atoms and iso-propyl methyl groups are removed for clarity. Selected bond lengths ( $(\AA)$ and angles $\left({ }^{\circ}\right)$ : Sn1-Ca1' 3.3221(5), Sn1C34 2.222(3), Sn1-C36 2.218(3), Sn1-C42 2.196(3), Ca1-N1 2.319(2), Ca1-N2 2.330(2), Ca1-C34 2.987(3), Ca1-C35 2.917(3), C34-Sn1-Ca1' 130.80(8), C36-Sn1-Ca1' 122.05(9), C36-Sn1-C34 94.66(12), C42-Sn1-Ca1' 111.37(9), C42-Sn1-C34 92.91(11), C42-Sn1-C36 97.30(12), N1-Ca1-N2 82.69(8). Symmetry operations to generate primed atoms; $1-x, 1-y, 1-z$

Dimer propagation occurs in a similar manner, through twofold $\eta^{6}$ phenyl-to-calcium interactions, albeit the Ca-centroid distance in $\mathbf{4}$ is slightly shorter at $2.5376(19) \AA$. The presence of the more sterically demanding triphenylstannyl ligand in the place of the bridging hydride of 3 also induces some significant geometric adjustments at the calcium centre, which projects some 1.339(3) A out of the mean plane defined by $\mathrm{N} 1 / \mathrm{N} 2 / \mathrm{C} 1-\mathrm{C} 5$ of the BDI ligand. In addition, although the geometry at tin is somewhat distorted from a perfect tetrahedron, the three C-Sn-C and Ca-Sn-C angles fall within a much closer range (92.9-97.3 ${ }^{\circ}$ and $111.4-130.8^{\circ}$, respectively) than those imposed by the trigonal pyramidal geometry of compound 3 .

The electronic structures of compounds $\mathbf{3}$ and $\mathbf{4}$ were assessed by Density Functional Theory (DFT, see ESI $\dagger$ for full details of methodology). The HOMOs of both compounds are of a similar energy ( $c a .-4.45 \mathrm{eV}$, see Fig. S20, ESI $\dagger$ ) and, emphasising the highly ionic nature of the Ca-Sn bonding, effectively comprise donation of the filled tin $5 p$ orbitals to the cationic calcium centre(s) (Fig. 3). The Ca-arene interactions (3: HOMO-27, HOMO-28; 4: HOMO-21, HOMO-22) are also largely electrostatic in nature and originate from interactions between the Lewis acidic tin centres and the almost degenerate pair of highest energy filled $\pi$-orbitals associated with the coordinated $\mathrm{C}_{6} \mathrm{H}_{5}$ rings (Fig. S20, ESI $\dagger$ ).

The reaction between compound 1 and $\mathrm{Ph}_{3} \mathrm{SnH}$ was also investigated by DFT. Although a pathway (Fig. S22, ESI $\dagger$ ) invoking fragmentation of the dimeric hydride (1) was considered, the initial monomerisation process was found to be significantly endergonic $\left(\Delta G=+33.7 \mathrm{kcal} \mathrm{mol}^{-1}\right)$. A more viable pathway was computed to occur without any necessary dimer fragmentation (Fig. 4a). In this case, although formation of encounter complex $\mathbf{A}$ is endergonic by $+7.6 \mathrm{kcal} \mathrm{mol}^{-1}$, consistent with the observed facility
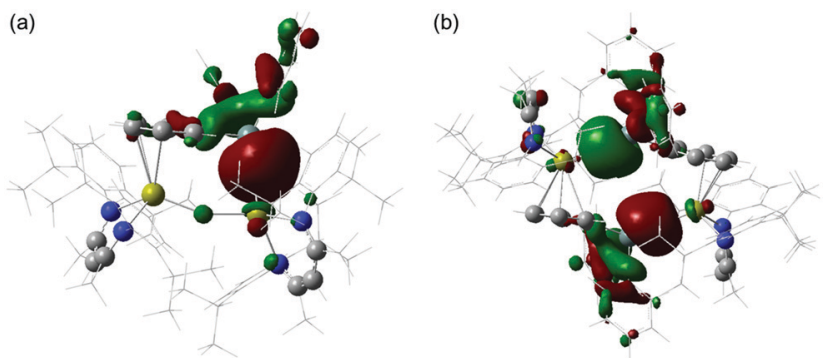

Fig. 3 Computed HOMOs (BP86/BS1) $)^{19}$ for (a) 3 and (b) 4 .

of the reaction at room temperature, the $\mathrm{Sn}-\mathrm{H}^{\mathrm{a}}$ bond and $\mathrm{Ca}-\mathrm{H}^{\mathrm{b}}$ bonds are broken via a dinuclear transition state $\mathbf{T S}_{\mathbf{A B}}$ at only $+8.3 \mathrm{kcal} \mathrm{mol}^{-1}$. Natural Bond Orbital (NBO) analysis of $\mathbf{T S}_{\mathbf{A B}}$ indicated partial charges of -0.03 and -0.25 on $\mathrm{H}^{\mathrm{a}}$ and $\mathrm{H}^{\mathrm{b}}$, respectively (Fig. 4b), emphasising that $\mathrm{H}_{2}$ elimination results from what is essentially an acid-base reaction where $\mathrm{Ph}_{3} \mathrm{SnH}$ is deprotonated by the calcium hydride. The newly formed $\mathrm{H}-\mathrm{H}$ bond in the subsequent intermediate $\mathbf{B}$ remains substantially polarised, with partial charges of $+0.01\left(\mathrm{H}^{\mathrm{a}}\right)$ and $-0.27\left(\mathrm{H}^{\mathrm{b}}\right)$. Isomerisation via $\mathbf{C}$ and dihydrogen loss provides species $\mathbf{D}$ at $-11.9 \mathrm{kcal} \mathrm{mol}^{-1}$, from which 3 is formed $\left(\Delta G=-26.7 \mathrm{kcal} \mathrm{mol}^{-1}\right)$ through realisation of the $\mathrm{Ca}-\pi$ arene interaction. Assessment of the reaction of 3 with a second molecule of $\mathrm{Ph}_{3} \mathrm{SnH}$ (Fig. S23, ESI $\dagger$ ) indicated that the formation of $\mathbf{4}$ occurs via a similarly polarised and kinetically

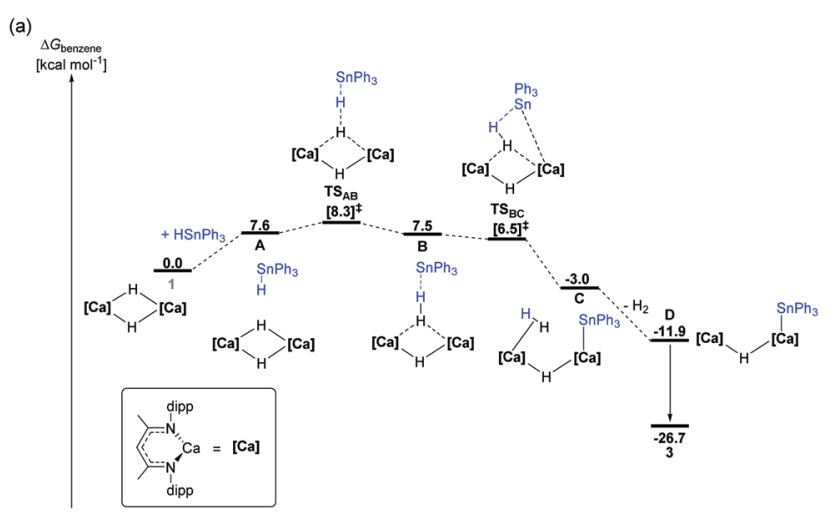

(b)

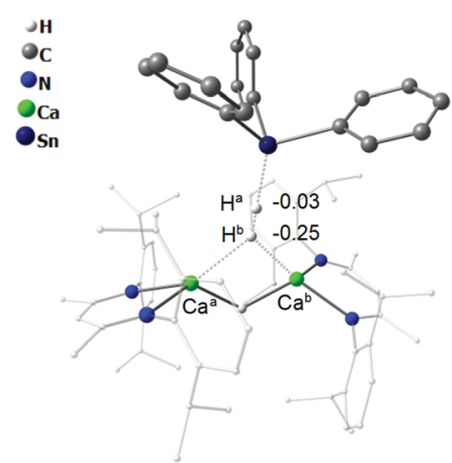

Fig. 4 (a) DFT calculated (BP86-D3(BJ)-benzene/BS2//BP86/BS1) ${ }^{19}$ free energy ( $\mathrm{kcal} \mathrm{mol}{ }^{-1}$ ) profile for the reaction of 1 with $\mathrm{HSnPh}_{3}$ to form 3 , relative to $1+\mathrm{HSnPh}_{3}$; (b) transition state $\mathrm{TS}_{\mathrm{AB}}$ showing calculated $\mathrm{NBO}$ charges of $\mathrm{H}^{\mathrm{a}}$ and $\mathrm{H}^{\mathrm{b}}$. BDI ligand frameworks shown as wireframe for clarity. 
accessible transition state leading to $\mathrm{H}_{2}$ elimination $\left(\Delta G^{\ddagger}=\right.$ $-12.1 \mathrm{kcal} \mathrm{mol}^{-1}$ ).

Further experiments to scale up and optimise the synthesis of 3 and $\mathbf{4}$ were hampered by the co-crystallisation of both compounds and the facility of the system toward redistribution of the triphenylstannane reagent to $\mathrm{Ph}_{4} \mathrm{Sn}$ and metallic tin. We tentatively suggest that the production of elemental tin may be ascribed to the dismutation of the $\mathrm{Ph}_{3} \mathrm{SnH}$ reagent to $\mathrm{Ph}_{4} \mathrm{Sn}$ and unstable $\mathrm{SnH}_{4}$, which further eliminates $\mathrm{H}_{2}$. Under this regime, compound 3 undergoes $\mathrm{Sn}-\mathrm{Ph} / \mathrm{Sn}-\mathrm{H}$ metathesis, possibly facilitated by the polarisation of a $\mathrm{Sn}-\mathrm{C}$ bond through its interaction with the highly electropositive calcium centre, more rapidly than further stannane deprotonation to form 4 . This process provides $\mathrm{Ph}_{4} \mathrm{Sn}$ and a calcium diphenylstannyl derivative, [(BDI)Ca- $\mu_{2}-\mathrm{H}-$ $\left.\left(\mathrm{SnPh}_{2} \mathrm{H}\right) \mathrm{Ca}(\mathrm{BDI})\right]$, which is unobservable due to its rapid consumption by analogous reaction with $\mathrm{Ph}_{3} \mathrm{SnH}$. Consecutive and increasingly facile reactions of this nature ultimately provide a parent calcium stannane derivative, [(BDI)Ca- $\left.\mu_{2}-\mathrm{H}-\left(\mathrm{SnH}_{3}\right) \mathrm{Ca}(\mathrm{BDI})\right]$. This species will be prone to further $\mathrm{Sn}-\mathrm{H} / \mathrm{Ca}-\mathrm{Sn}$ metathesis to reform compound 1 and produce unstable $\mathrm{SnH}_{4}$ with the consequent generation of $\mathrm{H}_{2}$ and elemental tin. Although no further calcium- or tin-centred intermediates could be observed, support for this hypothesis was provided by a further reaction between compound 3 and $n$-Bu $\mathrm{Bu}_{3} \mathrm{SnH}$. Monitoring by ${ }^{1} \mathrm{H}$ and ${ }^{119} \mathrm{Sn}\left\{\left\{{ }^{1} \mathrm{H}\right\} \mathrm{NMR}\right.$ spectroscopy over 40 hours, during which time the reaction again became black and opaque, confirmed that quantitative conversion of $\mathrm{Bu}_{3} \mathrm{SnH}$ to $\mathrm{Bu}_{3} \mathrm{SnPh}$ had occurred.

We are continuing to assess these possibilities and to study the reactivity of the resultant calcium stannyl and related p-block centred anions.

We acknowledge financial support from the EPSRC Centre for Doctoral Training in Catalysis (EP/L016443/1) and research grant EP/R020752/1. This research made use of the Balena High Performance Computing (HPC) Service at the University of Bath. I. M. thanks the University of Bristol for support and the Canadian Government for a Canada 150 Research Chair.

\section{Conflicts of interest}

There are no conflicts to declare.

\section{Notes and references}

1 (a) A. G. M. Barrett, M. R. Crimmin, M. S. Hill and P. A. Procopiou, Proc. R. Soc. A, 2010, 466, 927-963; (b) S. Harder, Chem. Rev., 2010, 110, 3852-3876; (c) M. R. Crimmin and M. S. Hill, in Alkaline-Earth Metal Compounds: Oddities and Applications, ed. S. Harder, 2013, vol. 45, pp. 191-241; (d) M. S. Hill, D. J. Liptrot and C. Weetman, Chem. Soc. Rev. , 2016, 45, 972-988; (e) Y. Sarazin and J. F. Carpentier, Chem. Rec., 2016, 16, 2482-2505.

2 (a) D. Mukherjee, D. Schuhknecht and J. Okuda, Angew. Chem., Int. Ed., 2018, 57, 9590-9602; (b) S. Harder and J. Brettar, Angew. Chem., Int. Ed., 2006, 45, 3474-3478; (c) P. Jochmann, J. P. Davin, T. P. Spaniol, L. Maron and J. Okuda, Angew. Chem., Int. Ed., 2012, 51, 4452-4455; (d) V. Leich, T. P. Spaniol and J. Okuda, Inorg. Chem., 2015, 54, 4927-4933; (e) D. Schuhknecht, C. Lhotzky, T. P. Spaniol, L. Maron and J. Okuda, Angew. Chem., Int. Ed., 2017, 56, 12367-12371; $(f)$ B. Maitland, M. Wiesinger, J. Langer, G. Ballmann, J. Pahl, H. Elsen, C. Farber and S. Harder, Angew. Chem., Int. Ed., 2017, 56, 11880-11884; $(g)$ A. Causero, G. Ballmann, J. Pahl, H. Zijlstra, C. Farber and S. Harder, Organometallics, 2016, 35, 3350-3360.

3 V. Leich, T. P. Spaniol, L. Maron and J. Okuda, Angew. Chem., Int. Ed., 2016, 55, 4794-4797.

4 For example, (a) J. Spielmann, F. Buch and S. Harder, Angew. Chem., Int. Ed., 2008, 47, 9434-9438; (b) J. Spielmann and S. Harder, J. Am. Chem. Soc., 2009, 131, 5064-5065; (c) M. D. Anker, M. S. Hill, J. P. Lowe and M. F. Mahon, Angew. Chem., Int. Ed., 2015, 54, 10009-10011; (d) M. D. Anker, C. E. Kefalidis, Y. Yang, J. Fang, M. S. Hill, M. F. Mahon and L. Maron, J. Am. Chem. Soc., 2017, 139, 10036-10054.

5 A. S. S. Wilson, M. S. Hill, M. F. Mahon, C. Dinoi and L. Maron, Science, 2017, 358, 1168-1171.

6 (a) A. S. S. Wilson, M. S. Hill and M. F. Mahon, Organometallics, 2019, 38, 351-360; (b) A. S. S. Wilson, C. Dinoi, M. S. Hill, M. F. Mahon and L. Maron, Angew. Chem., Int. Ed., 2018, 57, 15500-15504; (c) M. S. Hill, M. F. Mahon, A. S. S. Wilson, C. Dinoi, L. Maron and E. Richards, Chem. Commun., 2019, 55, 5732-5735.

7 B. Rosch, T. X. Gentner, H. Elsen, C. A. Fischer, J. Langer, M. Wiesinger and S. Harder, Angew. Chem., Int. Ed., 2019, 58, 5396-5401.

8 T. Komiyama, Y. Minami and T. Hiyama, ACS Catal., 2017, 7, 631-651.

9 (a) P. Espinet and A. M. Echavarren, Angew. Chem., Int. Ed., 2004, 43, 4704-4734; (b) M. M. Heravi and L. Mohammadkhani, J. Organomet. Chem., 2018, 869, 106-200.

10 (a) D. Reed, D. Stalke and D. S. Wright, Angew. Chem., Int. Ed. Engl., 1991, 30, 1459-1460; (b) P. B. Hitchcock, M. F. Lappert, G. A. Lawless and B. Royo, J. Chem. Soc., Chem. Commun., 1993, 554-555; (c) B. E. Eichler, A. D. Phillips and P. P. Power, Organometallics, 2003, 22, 5423-5426; (d) T. Schollmeier, U. Englich, R. Fischer, I. Prass, K. Ruhlandt-Senge, M. Schurmann and F. Uhlig, Z. Naturforsch., B: J. Chem. Sci., 2004, 59, 1462-1470; (e) C. Kleeberg, J. Grunenberg and X. L. Xie, Inorg. Chem., 2014, 53, 4400-4410; $(f)$ J. Jastrzebski, M. van Klaveren and G. van Koten, Organometallics, 2015, 34, 2600-2607.

11 (a) W. J. Teng and K. Ruhlandt-Senge, Organometallics, 2004, 23, 2694-2700; (b) W. J. Teng and K. Ruhlandt-Senge, Organometallics, 2004, 23, 952-956; (c) V. Leich, T. P. Spaniol, L. Maron and J. Okuda, Chem. Commun., 2014, 50, 2311-2314; (d) N. L. Lampland, A. Pindwal, K. K. Yan, A. Ellern and A. D. Sadow, Organometallics, 2017, 36, 4546-4557.

12 M. Westerhausen, Angew. Chem., Int. Ed. Engl., 1994, 33, 1493-1495. 13 U. Englich, K. Ruhlandt-Senge and F. Uhlig, J. Organomet. Chem., 2000, 613, 139-147.

14 B. Wrackmeyer, Annu. Rep. NMR Spectrosc., 1999, 38, 203-264.

15 (a) S. C. Rosca, C. Dinoi, E. Caytan, V. Dorcet, M. Etienne, J. F. Carpentier and Y. Sarazin, Chem. - Eur. J., 2016, 22, 6505-6509; (b) S. C. Rosca, E. Caytan, V. Dorcet, T. Roisnel, J. F. Carpentier and Y. Sarazin, Organometallics, 2017, 36, 1269-1277; (c) S. C. Rosca, V. Dorcet, T. Roisnel, J. F. Carpentier and Y. Sarazin, Dalton Trans., 2017, 46, 14785-14794; (d) S. C. Rosca, V. Dorcet, J. F. Carpentier and Y. Sarazin, Inorg. Chim. Acta, 2018, 475, 59-64; (e) M. F. Zuniga, G. B. Deacon and K. Ruhlandt-Senge, Inorg. Chem., 2008, 47, 4669-4681; $(f)$ W. D. Buchanan, D. G. Allis and K. Ruhlandt-Senge, Chem. Commun., 2010, 46, 4449-4465.

16 (a) L. Garcia, M. D. Anker, M. F. Mahon, L. Maron and M. S. Hill, Dalton Trans., 2018, 47, 12684-12693; (b) L. Garcia, M. S. Hil and M. F. Mahon, Organometallics, 2019, DOI: 10.1021/acs.organomet.9b00493.

17 (a) J. Pahl, S. Brand, H. Elsen and S. Harder, Chem. Commun., 2018, 54, 8685-8688; (b) J. Pahl, A. Friedrich, H. Eisen and S. Harder, Organometallics, 2018, 37, 2901-2909.

18 (a) C. Loh, S. Seupel, H. Görls, S. Krieck and M. Westerhausen, Organometallics, 2014, 33, 1480-1491; (b) C. Loh, S. Seupel, A. Koch, H. Görls, S. Krieck and M. Westerhausen, Dalton Trans., 2014, 43, 14440-14449; (c) S. O. Hauber, F. Lissner, G. B. Deacon and M. Niemeyer, Angew. Chem., Int. Ed., 2005, 44, 5871-5875.

19 BS1 = SDDALL for Ca and Sn, 6-31G** for all other atoms, BS2 = ccpVTZ for Ca, cc-pVTZ-PP for Sn and $6-311++\mathrm{G}^{* *}$ for all other atoms. 